\title{
Working memory and its relation to achievement motivation among academically outstanding students at the faculty of education, Majmaah university
}

\author{
${ }^{1}$ Mai Fathi Al-Baghdadi, ${ }^{2}$ Eman Mahmoud El Ashmawy \\ ${ }^{1,2}$ Teaching staff at the Department of Special Education, Faculty of Education, Majmaah \\ University, KSA \\ ${ }^{1}$ nemnem_m@yahoo.com
}




\title{
Working Memory and its Relation to Achievement Motivation among Academically Outstanding Students at the Faculty of Education, Majmaah University
}

\author{
Mai Fathi Al-Baghdadi ${ }^{1^{*}}$, Eman Mahmoud El Ashmawy ${ }^{2}$ \\ ${ }^{1,2}$ Teaching staff at the Department of Special Education, Faculty of Education, \\ Majmaah University, KSA \\ 1nemnem_m@yahoo.com
}

Received: $16^{\text {th }}$ Sept 2020 Revised: $14^{\text {th }}$ Jan 2021 Accepted: $5^{\text {th }}$ Feb 2021 DOI: https://doi.org/10.31559/CCSE2021.2.1.2

Abstract: The current study aimed to identify the relationship between the working memory and its tasks (Audio Numbers - Category Classification - Visual Matrix - Maps \& Directions), and achievement motivation among academically outstanding students, the study sample consisted of 60 students (GPA $=4.5$ and above), who were academically outstanding in the faculty of Education, the Majmaah University from different departments. By using Working Memory and Achievement motivation tests, the results were extracted by the SPSS program indicated: There is a positive statistically significant relationship at the level $(0.05)$ between the achievement motivation and working memory tasks, and the presence of a positive statistically significant relationship at (0.001) level between achievement motivation and memory of maps and directions.

Keywords: Working memory; Achievement motivation; Academically Outstanding Students.

${ }^{*}$ Corresponding author

Mai Fathi Al-Baghdadi

Teaching staff at the Department of Special Education, Faculty of Education, Majmaah University, KSA

E-mail: nemnem_m@yahoo.com 
International Journal of Childhood, Counselling, \& Special Education (CCSE), Volume2, Issue: 1, March: 2021, pp.16-34

\section{Introduction}

Human societies are focusing on achieving the desirable benefit of their human and various energies, as human wealth no less important than natural resources, as some societies and states see that human energy is the means of development and that its first tools are academically outstanding students, they like other members of society, that have their motivations, physical needs, psychological and social and that seek to satisfy them. The extent of their adaptation to the degree of satisfaction of those needs to reach a better level of social adjustment, and not being able to satisfy these needs leads to negative results (Abdullah, 2010). Academic excellence is an important factor of social change, scientific and technological progress that the society seeks to achieve its abilities and potentials among different societies through the ability of its outstanding children and their characteristics to push their society towards advancement (Qandi, 2017). This is through their internal motivation, which is the motivation for achievement and exerts more effort, which affects academic excellence (AlBaghdadi, 2010).

Also, the University is responsible for the development of human thought to its highest level and the source of inspiration for applying of scientific theories and development preservation of human values in integration with the national culture values in a manner that preserves the national character of its society that is responsible for the students' growth and the community leaders return who listen to the future of the nation based on the philosophy of the nation and its view of life, As well as importance of university education not only to the present but also to the future and the ability to face difficulties and to meet challenges (Mezied, 2005).

Achieving success and the desire to progress than others is part of the lives of most students, since academic achievement has serious consequences such as college admission, graduation, and obtaining an appropriate job which affects the motivation to achievement, cognitive performance of the student, such as working memory, which affected by the student ability has information retention, the ability to perform complex tasks, and academic achievement (Crouzevialle, Smeding, \& Butera. 2015). As the educational environment inside the university works that every student has an acceptable level of cognitive competence while employing the tasks of working memory in academic achievement and various activities (Rodrigo \& Tabuenca, 2020).

Working memory is also one of the most important variables of information processing in the human mind as it represents a dynamic active system that works through a proactive focus on processing and storage requirements and concerned with the interpretation, integration, and current information interconnection with previously stored or retained information (Buckley, Seery \& Canty, 2018). Working memory is an active part of the information processing system. It is responsible for both 
International Journal of Childhood, Counselling, \& Special Education (CCSE), Volume2, Issue: 1, March: 2021, pp.16-34

storage and processing functions, and some believe that it has a place in the brain where information processing, interpretation, and storage are handled and vary from person to person. The new information interacts with information retrieved from long-term memory to be organized, processed, and organized (Cowan, 2016).

\section{Study problem:}

Recent research has shown that the effective use of cognitive processing of working memory tasks distinguishes between superior and ordinary students (Gray, \& Holyoak, 2020). This is through executive performance, which is a component of working memory and which has an important role in increasing achieve motivation (Aidman, 2020), an internal process directing behavior, and many studies such as Mills, Covey, Shucard, \& Shucard (2019) \& Pajares \& Herron, (2007) \& Wischgoll, Pauli, \& Reusser2019) have confirmed a strong relationship between motivation and cognitive tasks, where motivation affects the use of Appropriate cognitive strategies.

The results of many studies agree that achievement motivation is an effective variable in student performance with high achievers in different cognitive processes, including working memory (Trigo et al. 2018). Research had shown that the higher cognitive abilities of individuals lead to skills proficiency, which increases the level of motivation achievement, selfconfidence and it can improve recall and cognitive processing speed (Leather\& McLoughlin, 2018).
It also indicates the importance of the self-organizing strategy for learning in student learning, which is one of the most important characteristics of outstanding students (Lawson, Vosniadou, Van Deur, Wyra, \& Jeffries, 2019)

Research Gray \& Holyoak (2020) has shown that the effective use of cognitive processing of working memory tasks makes a distinction between outstanding and un outstanding students.

González-Sanmamed, Sangrà, Souto-Seijo, and Blanco (2018) indicated the association with working memory and its various tasks with the high performance of individuals and the achievement motivation.

As Dunham (2011) referred that many serious challenges are facing outstanding students, and these challenges can be overcome through understanding and studying the mechanism of working memory and its relationship with achievement motivation.

\section{The problem of the study is identified} in the following:

1. Is there a relationship between Audio numbers memory and the achievement motivation among academically outstanding students at the Faculty of Education, Majmaah University?

2. Is there a relationship between Category Classification memory and the achievement motivation among academically outstanding students at the Faculty of Education, Majmaah University?

3. Is there a relationship between Visual Matrix memory and the 
International Journal of Childhood, Counselling, \& Special Education (CCSE), Volume2, Issue: 1, March: 2021, pp.16-34

achievement motivation among academically outstanding students at the Faculty of Education, Majmaah University?

4. Is there a relationship between the memory of maps and directions, and the achievement motivation among academically outstanding students at the Faculty of Education, Majmaah University?

The purpose of the study:

The current study aimed to:

1. To identify the relationship between working memory and its tasks (Audio numbers - Category Classification - Visual Matrix Maps \& Directions) and achievement motivation among academically outstanding students at the Faculty of Education, Majmaah University.

2. To identify the relationship between Audio numbers memory and the achievement motivation among academically outstanding students at the Faculty of Education, Majmaah University.

3. To identify the relationship between Category Classification memory and the achievement motivation among academically outstanding students at the Faculty of Education, Majmaah University.

4. To identify the relationship between Visual Matrix memory and the achievement motivation among academically outstanding students at the Faculty of Education, Majmaah University.

5. To identify the relationship between the memory of maps and directions, and the achievement motivation among academically outstanding students at the Faculty of Education, Majmaah University.

The studying importance:

The present study derives its importance from the following:

1. Attempt to shed light on academically outstanding university students and identify their characteristics.

2. The results of the study can be taken into consideration when studying the mental relations in the field of information processing among academically outstanding university students.

3. The importance of study variables, which include working memory, academic outstanding, achievement motivation which are variables that have a significant impact on the life of the individual.

\section{Review of the Literature}

\section{Working Memory:}

A mental process through, which information is stored, and processed for a temporary period, and made inactive form to achieve the cognitive activities requirements and complete of mental tasks (Okasha \& Amara, 2013).

Psychologists began using this concept as a replacement concept of short memory because it gives more accurate and realistic meaning in the light of its functions (Otoum, 2012).

The working memory idea appeared at first-time to researchers Miller and Alanter and Pribram in 1960., and considered studies conducted by Badley in working memory is the beginning of many 
International Journal of Childhood, Counselling, \& Special Education (CCSE), Volume2, Issue: 1, March: 2021, pp.16-34

researchers in this field, who suggested capacity of working memory limited that affects information processing during the performance different tasks and individual differences in working memory capacity refers to individuals with low-memory capacity perform less efficiently in various tasks with large capacity and differences in efficiency working memory depends on the extent to which information can be retained for a temporary period, searching for appropriate information in long-term memory, and processing them to suit the situation (Buckley, Seery, \& Canty, 2018).

Many cognitive theories pointed to the strong effects of mental images in mind and memory, such as verbal and non-verbal effects in memory, and were applied in the field of cognition, where anyone can learn new materials using verbal connections or visual images, but the combination of the two is more successful in learning, as the brain uses both visual and oral information to represent information. (Kanellopoulou, Kermanidis, \& Giannakoulopoulos, 2019).

\section{Working Memory Measurement:}

There are many ways to measure working memory, including "Simple Memory Span Tasks" it offers a series of stimuli, letters, words, numbers, forms, or places. The examinees are asked to call the same stimulant if asked but focus on the primary components of working memory. "Dual- Tasks" such as duple treatment related to the reading range and includes 60 non-linked sentences divided into three groups. The group is divided into six levels. The first level begins with two sentences and increases by one sentence with consecutive attempts at each level. Each sentence consists of 13-16 words. After reading the sentences in each level asked to call the last word of each sentence in the same order. The test stands at the level at which the individual fails in the three groups and the level at which he succeeds is a recording of the working memory capacity (Akasha \& Amara, 2013).

\section{Working memory components:}

Working memory is the processing center and represents the active part of the information processing system, responsible for both storage and processing functions (Solso, 2000).

It is components differ according to the theoretical perception addressed by it, includes the following, the central executive, a major system responsible for overseeing informationprocessing operations, assisted by two subsidiary systems: Verbal Articulatory component, which is responsible for the processing of linguistic information, as well as audio storage of information and verbal processing of it. The visual-spatial sketch component, which is responsible for processing visual-spatial information, (Cowan, 2016)

In the area of information processing, working memory plays an important role in processing top-level cognitive processes such as reasoning and Creative thinking. Several studies have confirmed that individual differences in working memory efficiency appear in tasks that require deep processing. (Honig, 2018). 
International Journal of Childhood, Counselling, \& Special Education (CCSE), Volume2, Issue: 1, March: 2021, pp.16-34

Several perceptions have confirmed that there is a working memory capacity that affects the performance of their functions that there are controls in the flow of information and the individual deals with them because of limited capacity. (Christophel, Iamshchinina, Yan, Allefeld, \& Haynes, 2018).

It is assumed that the interaction between the components of working memory provides the basis for understanding innovative thinking and the ability to conclude, and the interaction between these components allows continuous attempts to solve the problem, and from this standpoint, they called the working memory the mind's board which spatial-visual images are written in which the attempt occurs and return it when Discard the first solution and try the solution again. (Honig, 2018).

A study by Buckley, Seery, and Canty (2018) indicated a significant correlation between spatial ability as a component of working memory and high academic performance.

A study by Nowbakht (2019) Confirmed that the working memory is an important indicator in determining the rapid level of language and understanding linguistic sentences as well as increasing the achievement motivation in the learning process. The current research focuses on the study of working memory components by focusing on some tasks of verbal working memory (represented in the functions of audit preparation and classification function), and non-verbal working memory (represented in the visual matrix mission, maps, and directions task.

\section{Achievement motivation:}

Achievement motivation is a readiness of the individual to strive for outstanding, approach to success, desire to perform well, perseverance, overcome difficulties and achieve a specific goal in situations that include levels of excellence and outstanding. (Al-Ghamdi, 2009). It is an introduction to the recognition process, and an important outcome of education (Feldon, Callan, Juth, \& Jeong, 2019).

Plass and Kalyuga (2019) indicated that achievement motivation is greatly affected by some non-cognitive variables such as emotions, which directly affect memory through the expansion or narrowing of cognitive resources, and through certain mechanisms such as mood, and therefore regulation of emotions is part of the learning outcomes, and the study indicated that emotions effect on achievement motivation, and thus affect mental effort as a result of its impact on the cognitive burden.

Recent studies have shown that achievement motivation, organization, and perceived competence play a strong role in academic achievement (Hanin \& Van Nieuwenhoven, 2019).

\section{Dimensions of achievement motivation:}

The achievement motivation consists of the following dimensions: "Endurance - Perseverance - Social Participation - Control - Social Standards - Independence". These dimensions are achieved by University 
International Journal of Childhood, Counselling, \& Special Education (CCSE), Volume2, Issue: 1, March: 2021, pp.16-34

students through "Looking for success outstanding through effort and perseverance - Ability to achieve difficult business- Independence belonging to the group - keeping pace with the group and striving to achieve a distinguished position among others "(Karar, 2004).

\section{Working memory and achievement} motivation among academically outstanding university students:

Although intelligence is a trait common among many outstanding individuals, Terman (1925) found that the high IQ during the early years was not a strong indication of intelligence as the Character traits, achievement motivation, hard work and perseverance are more characteristic of the superior individuals compared to intelligence which represents strong beliefs and practices of individuals determine the level of success and failure (Paik, Choe, Otto \& Rahman, 2018).

Research has shown that the high cognitive and mental abilities of students lead to efficiency in mastering the skills, which increases the level of achievement motivation and thus selfconfidence and can improve recall and the speed of cognitive processing, which is a working memory skill (AlBaghdadi, 2010). Previous research confirms that working memory was an important and stable medium for the relationship between academic problems and achievement motivation in academic performance, which has a clear impact on academic achievement (Bedyńska, Krejtz, \& Sedek, 2019).

A study (Yeung, Ho, Chan, and Chung (2019) indicated that the motivation for achievement is an important indicator in the performance of verbal working memory tasks.

As Wongupparaj, Sumich, Wickens, Kumari, and Morris (2018) indicated that motivations, in general, stimulate the mental performance of the individual, and this explains the presence of a significant positive relationship between the achievement motivation and the efficiency of performance on the tasks of working memory.

The results of Dunham's (2011 \& )Chinnis (2016) study indicated that students with collectible high suffer sometimes from anxiety and that environmental perceptions and achievement motivation are the main factors affecting academic achievement, cognitive performance, and the relationship between working memory and achievement motivation.

Paik, Choe, Otto, and Rahman, (2018) also indicated the importance of achievement motivation and the environmental conditions that supporting academic outstanding.

A study by Jungert, Hubbard, Dedic, and Rosenfield (2019) pointed to the role of working memory in indirectly predicting the level of academic achievement and its continuation during achievement motivation and learning skills, which in turn affect academic outstanding.

Also, Lespiau, and Tricot, (2019) indicated that university students can obtain basic knowledge easily by doing more effort that is associated with increased performance efficiency and a higher level of achievement 
International Journal of Childhood, Counselling, \& Special Education (CCSE), Volume2, Issue: 1, March: 2021, pp.16-34

motivation, regardless of the personal characteristics of students or their ages.

And confirm Wischgoll, Pauli, and Reusser (2019) that the more complex the working memory tasks, the higher level of motivation in general and the achievement motivation for.

\section{Academic Outstanding:}

Academic Outstanding defined by the American National Education Association as being able to obtain continuous excellent or outstanding achievement in any field, which collective appreciation, as measured by achievement tests (Kneidi, 2017). It is also one aspect that needs continuous support by planning to adopt remedial approaches to the better needs of these students (Fisher, \& Kennedy, 2016). The talented individuals have been described as having exceptionally high abilities and achievements "in addition to academic performance (Cross \& Cross, 2015).

1. Characteristics of gifted and talented students:

The gifted students enjoy a variety of characteristic that differs from their normal peer by "Cognitive Characteristics" Outstanding students have characterized a mental high ability, as these capabilities able to grow and development, or latency depending on the degree of their motivations, and the other cognitive capabilities the ability to deal with For symbolism systems and abstract ideas, curiosity, independence in working, the memory strength- the love of reading, variety of interests and hobbies, early language capabilities.
"Emotional Properties" is the ability to control personal, social, and emotional aspects, and the ability to interact with others and control emotions and feelings and reactions in the event of exposure to stressful situations and these emotions can contribute to controlling the feelings and thinking of the student, and the organization of his academic life and outstanding students are characterized by emotional reliability, selfindependence, skills Leadership, moral maturity, sense of humor, leadership skills, and emotional hypersensitivity. (Makhlouf, 2009\& Jarwan 2013 \& 2016\& Alalala, Alalala ,2014 \& Renzulli, Siegle, Reis, Gavin, \& Reed $2009 \&$ Hakkarainen, Hytönen, Lonka, \& Makkonen 2014).

2. The characteristics of these students can be identified:

"They have a great Linguistic outcome, a wide knowledge about various and different topics, a strong memory, ability to understand the cause-and-effect relationships quickly, ability to understand and conclusion rules and regulations, characterized clever and promptitude, a passion for reading in a variety of fields, ability to understand objects and multiple topics by partitioning them into different elements (Alshakhs, 2015).

\section{Methods:}

\section{Participants and Procedure:}

The sample of the study: The study sample consisted of 60 students who were academically outstanding in the Faculty of Education in the Majmaah university from different departments, and they obtained an accumulation 
International Journal of Childhood, Counselling, \& Special Education (CCSE), Volume2, Issue: 1, March: 2021, pp.16-34

rate of 4.5 and above. Quantitative design is used in this study. Rationing was made to confirm the study tools (working memory and achievement motivation scales). Obtaining a statement of the academic outstanding students according to their academic rate in each department in the faculties of the Faculty of Education in Majmaah. The researchers applied the study tools represented in (working memory tasks and achievement motivation scales) which were distributed by paper. Data was entered and statistically processed by the SPSS program, and then the data was analyzed, interpreted, and discussed. Extraction of suitable recommendations and research proposals considering the results of the study.

\section{Variables:}

In this study the variables are:

The independent variable: the achievement motivation among the students who outstanding academically at the Faculty of Education, Majmaah University.

The dependent variable: It is the working memory of the academically outstanding students at the Faculty of Education, Majmaah University

\section{Measures:}

\section{The Working Memory Test prepared by Al-Baghdadi (2010):}

Scale description: The scale consists of four tasks. "The audio number task" (the subject and number task): This test aims to measure the capacity of the audio working memory by remembering a group of numbers mentioned in ten phrases, and each phrase has more numbers than that precedes it by one number, and the first phrase contained two numbers, the second is three numbers, and so on until the tenth sentence in which the number of numbers reached twelve.

"The Category Classification task" this task aims to measure the efficiency of working memory through the individual ability to classify semantic information, and this task contains eight groups, the first group begins with four words, each two belonging to one category, and the number of words in each group increases from the previous one at the rate of a word, until it reaches (18) words in the last group distributed into four semantic categories: home furniture, electrical appliances, insects and agricultural machinery.

"Measuring visual memory capacity through the visual matrix task" this task aims to measure the efficiency of working memory through the ability of the examined to remember spatialvisual and consists of matrices and each matrix contains many squares, their number varies from one matrix to another and in each matrix there are many symbols or shapes distributed in their cells with a certain type and the number of these matrices ten matrices and the first matrix begins with four squares and two symbols, and each matrix increases from the matrix preceding it with two squares and symbol and the last matrix end with twenty-four squares and eleven symbols.

"Measuring spatial memory capacity through maps and directions task" this task aims to measure the 
International Journal of Childhood, Counselling, \& Special Education (CCSE), Volume2, Issue: 1, March: 2021, pp.16-34

efficiency of spatial working memory through the ability to remember places from where their location and directions on two maps, and it consists of two maps include a group of streets in the original directions such as North, South, East, and West, and streets in sub-directions (North-East, South- East), and the map includes places and institutions such as (school, club, and market).

Scale Correction, the student is given a score for each correct answer, and zero for the wrong answer.

\section{Achievement Motivation Test, prepared} by Al-Baghdadi, Al-Shaarawi, 2013:

It aims to determine the level of student motivation achievement, the tasks entrusted to them, that everyone varies his desire and ability according to his motivation to learn.

\section{Psychometric verification of current study tools:}

The two researchers verified the psychometric efficacy of the working memory scale and the achievement motivation as: "Test-Retest Reliability" the working memory measures have been calculated through the reapplication of the measures by two weeks' time interval on the exploratory sample, and the correlation degrees between the sample degrees were extracted using the Pearson's coefficient, the following table shows this.

Table (1): Pearson's Correlation Coefficient for Scales of Working Memory and Achievement Motivation

\begin{tabular}{cc}
\hline The Test & Pearson Coefficient \\
\hline Working Memory & 0.83 \\
\hline Achievement Motivation & 0.88
\end{tabular}

Through the above table, it is clear that the correlation coefficient between the first and second applications of the working memory scale $(0.83)$ and the achievement motivation scale (0.88), there was significant at the level of 0.01 , which refers that the two scales give almost the same results if used under similar conditions It was clear from the previous that there is a statistically significant correlation between the first and second application of scales of the achievement motivation and the working memory, which indicates the reliability of the scales.

"Calculating Cronbach's Alpha Coefficients" the reliability coefficient for scales of the working memory and the achievement motivation was calculated by using the Cronbach's alpha coefficient to study the internal consistency of the scale, according to the study sample and the following table shows that. 
International Journal of Childhood, Counselling, \& Special Education (CCSE), Volume2, Issue: 1, March: 2021, pp.16-34

Table (2): Cronbach's Alpha Coefficients for The Working Memory and Achievement Motivation Scales

\begin{tabular}{cc}
\hline The Test & Cronbach's alpha coefficients \\
\hline Working Memory & 0.74 \\
\hline Achievement Motivation & 0.77
\end{tabular}

From the above table, it became clear that the Cronbach's alpha coefficient of the working memory test (0.74) and the drive for achievement test (0.77), which indicates that the scales enjoy a high and acceptable degree of reliability, which indicates the reliability of the scale and its suitability for use in the current study.

"Split-half reliability", the two researchers applied the scale of working memory and achievement motivation, and the two scales were corrected, then each scale was split into two parts. The first section included individual vocabulary, and second the marital vocabulary, that for everyone separately. The correlation coefficient was then calculated by the Pearson method by the degrees of examiners in individual vocabulary and their degrees in the marital vocabulary. The value of the Spearman-Brown coefficient and the Gettman coefficient of split-half was high, and this indicates that the scale has a high degree of reliability and the following table shows this.

Table (3): Reliability Coefficient of the Working Memory Measure in Split-half Method

\begin{tabular}{ccc}
\hline The Test & $\begin{array}{c}\text { Spearman-Brown } \\
\text { Coefficient }\end{array}$ & Gettman \\
\hline Working Memory & 0.84 & 0.77 \\
\hline $\begin{array}{c}\text { Achievement } \\
\text { Motivation }\end{array}$ & 0.86 & 0.79 \\
\hline
\end{tabular}

From the above table, it became clear the coefficient's reliability scale for each section from sections split-half Spearman-Brown Similar to the Getman method indicating that the scale has a high degree of reliability in its measurement of working memory.

\section{Statistical analysis:}

For data analysis, Correlation Coefficient Statistical processing was used by the SPSS program.

\section{Data Analysis:}

1. Table 4 presents" correlation coefficient was used to identify the relationship between Audio numbers memory and achievement motivation among academically outstanding students from the Faculty of Education in Majmaah through the following tables: 
International Journal of Childhood, Counselling, \& Special Education (CCSE), Volume2, Issue: 1, March: 2021, pp.16-34

Table (4): The Correlation Coefficient Between "Audio Number Memory" and Achievement Motivation Among Academically Outstanding Students from The Faculty of Education in Majmaah

\begin{tabular}{|c|c|c|}
\hline $\begin{array}{l}\text { Statistical Indicators } \\
\text { Variables }\end{array}$ & $\begin{array}{l}\text { Correlation } \\
\text { Coefficient }\end{array}$ & $\begin{array}{l}\text { Significance } \\
\text { Standard }\end{array}$ \\
\hline Achievement Motivation & 0.264 & Sig \\
\hline Audio Numbers Memory & & 0.05 \\
\hline
\end{tabular}

It is clear from the previous table that there is a positive relationship of statistical significance at the significance level (0.05) between the achievement motivation and the memory of auditory numbers, this can be explained that the level rise of outstanding student's audio number memory, led to rising in achievement motivation.

Table (5): The Correlation Coefficient Between "Category Classification Memory" and The Achievement Motivation Among Academically Outstanding Students from The Faculty of Education in Majmaah

\begin{tabular}{ccc}
\hline Statistical Indicators & $\begin{array}{c}\text { Correlation } \\
\text { Coefficient }\end{array}$ & $\begin{array}{c}\text { Significance } \\
\text { Standard }\end{array}$ \\
\hline $\begin{array}{c}\text { Achievement Motivation } \\
\text { Category Classification } \\
\text { Memory }\end{array}$ & & Sig \\
\hline
\end{tabular}

It is clear from the previous table that there is a positive relationship of statistical significance at the significance level (0.05) between the achievement motivation and category classification memory. This can be explained that the level rise of outstanding student's category
2. Table 5 presents" correlation coefficient was used to identify the relationship between Category Classification memory and achievement motivation among academically outstanding students from the Faculty of Education in Majmaah through the following tables: classification memory, led to rising in achievement motivation.

3. Table 6 presents "correlation coefficient was used to identify the relationship between Visual Matrix memory and achievement motivation among academically outstanding students from the Faculty of Education in Majmaah through the following tables: 
International Journal of Childhood, Counselling, \& Special Education (CCSE), Volume2, Issue: 1, March: 2021, pp.16-34

Table (6): The Correlation Coefficient Between Visual Matrix Memory" and the Achievement Motivation Among Academically Outstanding Students from the Faculty of Education in Majmaah

\begin{tabular}{ccc}
\hline Statistical Indicators & $\begin{array}{c}\text { Correlation } \\
\text { Coefficient }\end{array}$ & $\begin{array}{c}\text { Significance } \\
\text { Standard }\end{array}$ \\
\hline $\begin{array}{c}\text { Achievement } \\
\text { Motivation }\end{array}$ & 0.323 & Sig \\
\cline { 1 - 2 } visual Matrix Memory & & 0.05 \\
& &
\end{tabular}

It is clear from the previous table that there is a positive relationship of statistical significance at the significance level (0.05) between the achievement motivation and visual matrix memory. This can be explained that the level rise of outstanding student's visual matrix memory, led to rising in achievement motivation.
4. Table 7 presents "the correlation coefficient was used to identify the relationship between the memory of maps and directions, and achievement motivation among academically outstanding students from the Faculty of Education in Majmaah through the following tables:

Table (7): The Correlation Coefficient Between "Memory of Maps and Directions "And the Achievement Motivation Among Academically Outstanding Students from The Faculty of Education in Majmaah

\begin{tabular}{ccc}
\hline Statistical Indicators & $\begin{array}{c}\text { Correlation } \\
\text { Coefficient }\end{array}$ & $\begin{array}{c}\text { Significance } \\
\text { Standard }\end{array}$ \\
\hline $\begin{array}{c}\text { Achievement } \\
\text { Motivation }\end{array}$ & 0.579 & Sig \\
\hline $\begin{array}{c}\text { maps and Directions } \\
\text { Memory }\end{array}$ & & 0.001 \\
& & \\
\hline
\end{tabular}

It is clear from the previous table that there is a positive relationship of statistical significance at the significance level (0.001) between the achievement motivation and memory of maps and directions. This can be explained that the level rise of outstanding student's memory of maps and directions, led to rising in achievement motivation.

\section{Results discussion:}

Statistical results show that there is a statistically significant relationship between achievement motivation and working memory with its various tasks "audio numbers memory - visual matrix memory - Category classification memory - the memory of maps and directions ", and it can be explained that the working memory is responsible for the efficiency of information processing when performing various cognitive tasks and non-knowledge like achievement motivation, the superior students enjoy a strong achievement motivation, it appears in the strong desire to achieve their goals and this is confirmed by many studies such as Kanellopoulou, 
International Journal of Childhood, Counselling, \& Special Education (CCSE), Volume2, Issue: 1, March: 2021, pp.16-34

Kermanidis, and Giannakoulopoulos, (2019). Which indicated a relationship between the visual and auditory working memory and achievement motivation as they are a powerful means of learning that is evident in "abstract information, Category classification, and identification by the student as hearing voices along with images supports the learning process, which affects the achievement motivation and leads to better remember, Studies are indicating that, in general, the working memory capacity can be increased when excitability to achievement motivation by using two sensory methods, "such as a phone number storing in the working memory audio and visual, that research in the multisensory processing in the working memory is an important field, so students may differ in their abilities to process information in different sensory ways, as some may rely on visual means and others on audio means.( Castelló-Tarrida, Cladellas-Pros \& Limonero-Garcia, 2019 \& Abakumova, Bakaeva, Grishina \& Dyakova, 2019 \& Spit \& Rispens 2019).

Whereas, the working memory capacity is positively related to the learning outcomes, and after it has been included as an important variable that affects academic outstanding, so that multitasking interferes with learning that the outstanding students were constantly more successful than others but suffered during the simultaneous multi-tasking (Kiewra, 2019) \& Rodríguez-Nieto, SánchezGonzález, \& Sánchez-Miranda, 2019).
This is confirmed by previous studies as a study Bedyńska, Krejtz and Sedek (2019) \& Chinnis (2016) \& Dunham (2011) \& Yeung, Ho, Chan, and Chung (2019) achievement Motivation is an important indicator in the performance of verbal working memory tasks.

Wischgoll, Pauli, and Reusser (2019) also confirmed that the more complex the working memory tasks, the higher the level of motivation in general and the achievement motivation.

And a study by Wongupparaj, Sumich, Wickens, Kumari, and Morris (2018) indicated that motivations, in general, stimulate the mental performance of the individual, and this explains the presence of a significant positive relationship between the achievement motivation and the efficiency of performance on the tasks of working memory.

\section{Conclusion}

The study indicated that was a positive relationship of statistical significance between the achievement motivation and both (Audio numbers memory- Category Classification memory - visual matrix memory- the memory of maps and directions).

Limitation of The Study: The study is determined by the sample of study that consisted of 60 students who were academically outstanding in the Faculty of Education, Majmaah university from different departments, and they obtained an accumulation rate of 4.5 and above. The study tools, the working memory test, prepared by 
International Journal of Childhood, Counselling, \& Special Education (CCSE), Volume2, Issue: 1, March: 2021, pp.16-34

Al-Baghdadi, 2010, and the Achievement Motivation test for prepared by Al-Baghdadi, 2015. The variables of the study, the achievement motivation, the outstanding academic students, working memory. The time, the first semester of the academic year 1440-1441 AH.

Recommendations: Stimulate working memory is essential for academically outstanding and Achievement Motivation during learning. focusing on developing technological tools, that include activities that facilitate, cognitive processes, among academic outstanding students, Interest in talent, and innovation motivation applications, as an introduction to distinguish outstanding students, in addition to, benefiting from the research results in building programs to develop innovative thinking, considering that working memory is one of the variables affecting it.

Interesting in the topic of working memory and its relationship to each (achievement motivation - selfsatisfaction - psychological and social compatibility ... etc.) among different samples within the society, in addition to considering positive support and psychological counseling for outstanding students when making different decisions regarding their professional and academic lives.

\section{References}

Abakumova, I., Bakaeva, I., Grishina, A., \& Dyakova, E. (2019). Active learning technologies in distance education of gifted students. International Journal of Cognitive Research

in Science, Engineering and Education, $7(1)$ 85-49. https://doi.org/10.5937/ijcrsee1901085a. Abdullah, F. (2010). Strategies of teachers in dealing with outstanding students in Government high schools from the point of view of teachers and managers. Master Thesis. University of Najah.

Aidman, E. (2020). Cognitive Fitness Framework: Towards Assessing, Training and Augmenting IndividualDifference Factors Underpinning High-Performance Cognition. Frontiers in Human Neuroscience, 13, 466. https://doi.org/10.3389/fnhum.2019.00 466.

Al-Atoum, A. (2012): Cognitive and Applied Psychology. Amman (Jordan): Dar Al-Masirah, 3.

Al-Baghdadi, M. (2010). Some variables of information processing and its relation to innovative thinking for students with learning disabilities. Ph.D . Cairo. Institute of Arabic Studies.

Al-Baghdadi, M. (2015). The achievement motivation and destination of control and their relationship with some modern educational strategies among a sample of low-achieving students. Shaqra University. Dawadmi Forum for Special Education.

Al-Ghamdi, G. (2009). Rational thinking, irrational thinking, selfconcept, and achievement motivation among a sample of highly educated and ordinary adolescents in the cities of Makkah and Jeddah. PhD thesis, Umm Al-Qura University

Alshakhs, A. (2015). Methods of identification on gifted mentally, talented and care developing their 
International Journal of Childhood, Counselling, \& Special Education (CCSE), Volume2, Issue: 1, March: 2021, pp.16-34

creative abilities. Second International Conference of the gifted and talented under the theme "Towards national strategies for the care of creative". United Arab Emirates University.

Bedyńska, S., Krejtz, I., \& Sedek, G. (2019). Chronic stereotype threat and mathematical achievement in age cohorts of secondary school girls: mediational role of working memory, and intellectual helplessness. Social Psychology of Education, 22(2), 321-335. https://doi.org/10.1007/s11218-019. 09478-6.

Buckley, J., Seery, N., \& Canty, D. (2018). A heuristic framework of spatial ability: A review and synthesis of spatial factor literature to support its translation into STEM education. Educational Psychology Review,30(3), 947 - 972, https://doi.org/10.1007/s10648. 018-9432-z.

Castelló -Tarrida, A., Cladellas-Pros, R., \& Limonero-Garcia, J. T. (2019). The role of knowledge structures in adult excellence. An approach from expert functioning.

Chinnis, K. L. (2016). The underperformance of gifted elementary school students (Doctoral dissertation, The University of North Carolina at Charlotte).

Christophel, T. B., Iamshchinina, P., Yan, C., Allefeld, C., \& Haynes, J. D. (2018). Cortical specialization for attended versus unattended working memory. Nature neuroscience, 21(4), 494-496, https://doi.org/10.1038/s41593018-0094-4.

Covey, T. J., Shucard, J. L., \& Shucard, D. W. (2019). Working memory training and perceptual discrimination training impact overlapping and distinct neurocognitive processes: Evidence from event-related potentials and transfer of training gains. Cognition, 182, 50-72, https://doi.org/10.1016/j.cognition.2018 .08 .012 .

Cowan, N. (2016). Working Memory Capacity: Classic Edition. Routledge.

Crouzevialle, M., Smeding, A., \& Butera, F. (2015). Striving for excellence sometimes hinders high achievers: Performance-approach goals deplete arithmetical performance in students with high working memory capacity. PloS one, 10(9), https://doi.org/10.1371/journal.pone.01376 29.

Cross, J. R., \& Cross, T. L. (2015). Clinical and mental health issues in counseling the gifted individual. Journal of Counseling $\mathcal{E}$ Development, 93(2),

https://doi.org/10.1002/j.1556-

6676.2015.00192.x.

Dunham, W. J. (2011). A comparison of the sequence of instruction to facilitate student learning and achievement of remedial mathematics classes. South Carolina State University. Feldon, D. F., Callan, G., Juth, S., \& Jeong, S. (2019). Cognitive load as motivational cost. Educational Psychology Review, 1-19.

Fisher, E. S., \& Kennedy, K. (2016). Counseling diverse populations in schools. New York: Oxford University Press.

Fleming, K. A., Heintzelman, S. J., \& Bartholow, B. D. (2016). Specifying associations between conscientiousness and executive functioning: Mental set shifting, not prepotent response inhibition or working memory 
International Journal of Childhood, Counselling, \& Special Education (CCSE), Volume2, Issue: 1, March: 2021, pp.16-34

updating. Journal of Personality, 84(3), 348-360,

https://doi.org/10.1111/jopy.12163.

Foster, J. L., Shipstead, Z., Harrison, T. L., Hicks, K. L., Redick, T. S., \& Engle, R. W. (2015). Shortened complex span tasks can reliably measure working memory capacity. Memory $\mathcal{E}$ cognition, 43(2), 226-236, https://doi.org/10.3758/s13421-0140461-7.

González-Sanmamed, M., Sangrà, A., Souto-Seijo, A., \& Blanco, E. (2018). Ecologías de aprendizaje en la Era Digital: desafíos para la Educación Superior.

Gray, M. E., \& Holyoak, K. J. (2020). Individual differences in relational reasoning. Memory $\mathcal{E}$ cognition, 48(1), 96-110, https://doi.org/10.3758/s13421019-00964-y.

Hakkarainen, K., Hytönen, K., Lonka, K., \& Makkonen, J. (2014). How Does Collaborative Authoring in Doctoral Programs Socially Shape Practices of Academic Excellence ? Talent Development $\mathcal{E}$ Excellence, 6(1).

Hanin, V., \& Van Nieuwenhoven, C. (2019). Emotional and motivational relationship of elementary students to mathematical problem-solving: a person-centered approach. European Journal of Psychology of Education,34(4), 705-730,

https://doi.org/10.1007/s10212-01800411-7.

Honig, W. K. (2018). Studies of working memory in the pigeon. In Cognitive processes in animal behavior (pp. 211-248). Routledge.

Jarwan, F. (2013). Methods of detection of gifted. 3, Amman, Dar AlFikr.
Jarwan, F. (2013). Detection methods for the gifted. Edition 3, Amman, Dar Al-Fikr.

Jarwan, F. (2016). Talent and excellence and creativity. 7, Amman, Dar Al-Fikr.

Jungert, T., Hubbard, K., Dedic, H., \& Rosenfield, S. (2019). Systemizing and the gender gap: examining academic achievement and perseverance in STEM. European Journal of Psychology of Education, 34(2), 479-500, https://doi.org/10.1007/s10212-0180390-0.

Kanellopoulou, C., Kermanidis, K. L., \& Giannakoulopoulos, A. (2019). The Dual-Coding and Multimedia Learning Theories: Film Subtitles as a Vocabulary Teaching Tool. Education Sciences, $\quad 9(3), \quad 210$, https://doi.org/10.3390/educsci9030210. Karrar, L. (2004). Some of the characteristics of the mentally outstanding and their detection standards in the model schools in Khartoum State. PhD thesis. Sudan.

Kenidi, R. (2017). The characteristics of the outstanding university student. Master Thesis, University of Mohammed Khudair Biskra.

Kiewra, K. A. (2019). Help Your Children SOAR to Academic Success. Parenting for High Potential, 8(1), 10-14. Lawson, M. J., Vosniadou, S., Van Deur, P., Wyra, M., \& Jeffries, D. (2019). Teachers' and students' belief systems about the self-regulation of learning. Educational Psychology Review, 31(1),

223-251, https://doi.org/10.1007/s10648-0189453-7.

Leather, C., \& McLoughlin, D. (2018). Adapting to Transitions: 
International Journal of Childhood, Counselling, \& Special Education (CCSE), Volume2, Issue: 1, March: 2021, pp.16-34

Metacognition and the Role of Expertise. Perspectives on Language and Literacy, 44(1), 33-36.

Lespiau, F., \& Tricot, A. (2019). Using Primary Knowledge: An Efficient Way to Motivate Students and Promote the Learning of Formal Reasoning. Educational Psychology Review, 1-24.

Makhlouf, H. (2009). The problems of the gifted and their relationship with psychosocial compatibility among the second-grade pupils of the basic education in Zlatin city. Unpublished MA thesis, Al-Muraqqab University, Libya.

Mezied, J. (2005). The impact of university study on the growth of personal characteristics as recognized by outstanding students and nonoutstanding students. Jordan. The Hashemite University.

Mills, N., Pajares, F., \& Herron, C. (2007). Self-efficacy of college intermediate French students: Relation to achievement and motivation. Language learning, 57(3), 417-442, https://doi.org/10.1111/j.14679922.2007.00421.x.

Nowbakht, M. (2019). The Role of Working Memory, Language Proficiency, and Learners' Age in Second Language English Learners' Processing and Comprehension of Anaphoric Sentences. Journal of psycholinguistic research, 48(2), 353-370, https://doi.org/10.1007/s10936-0189607-2.

Okasha, M\& Emara, M. (2013). Effectiveness of a training program to develop skills beyond memory on the performance of working memory during the solution of the problem in a sample of students of the Faculty of Education. P (6). (4).

Paik, S. J., Choe, S. M. M., Otto, W. J., \& Rahman, Z. (2018). Learning About the Lives and Early Experiences of Notable Asian American Women: Productive Giftedness, Childhood Traits, and Supportive Conditions. Journal for the Education of the Gifted, 41(2), 160-192, https://doi.org/10.1177/0162353218763 927.

Plass, J. L., \& Kalyuga, S. (2019). Four ways of considering emotion in cognitive load theory. Educational Psychology Review, 1-21.

Renzulli, J. S., Siegle, D., Reis, S. M., Gavin, M. K., \& Reed, R. E. S. (2009). An investigation of the reliability and factor structure of four new scales for rating the behavioral characteristics of superior students. Journal of Advanced Academics, 21(1), 84-108, https://doi.org/10.1177/1932202x09021 00105.

Rodríguez-Nieto, M. C., SánchezGonzález, A. S., \& Sánchez-Miranda, M. P. (2019). How Are the Gifted? Point of View of University Students. Educational Process. International Journal, $\quad 8(2), \quad 123$, https://doi.org/10.22521/edupij.2019.82 .3.

Rodrigo, C., \& Tabuenca, B. (2020). Ecologías de aprendizaje en estudiantes online con discapacidades. Comunicar. Revista cientifica iberoamericana de comunicación y educación, (62), 53-65.

Schmeichel, B. J., \& Demaree, H. A. (2010). Working memory capacity and spontaneous emotion regulation: High capacity predicts self-enhancement in 
International Journal of Childhood, Counselling, \& Special Education (CCSE), Volume2, Issue: 1, March: 2021, pp.16-34

response to negative feedback. motivational contingency with Emotion, 10(5), 739.

Sulso, R, Translation by Mohammed, increasing task complexity results in higher performance. Instructional S, Mustafa K\& Mohammed, A. (2000). Cognitive psychology. Second edition, Cairo: Anglo-Egyptian.

Spit, S., \& Rispens, J. (2019). On the Relation Between Procedural Learning and Syntactic Proficiency in Gifted Children. Journal of psycholinguistic research, 48(2), 417-429, https://doi.org/10.1007/s10936-0189611-6.

Trigo, J. M., Soliman, A., Quilty, L. C., Fischer, B., Rehm, J., Selby, P., ... \& Staios, G. (2018). Nabiximols combined with motivational enhancement/cognitive behavioral therapy for the treatment of cannabis dependence: A pilot randomized clinical trial. PloS one, 13(1), e0190768, https://doi.org/10.1371/journal.pone.01 90768.

Wischgoll, A., Pauli, C., \& Reusser, K. (2019). High levels of cognitive and

319-352, https://doi.org/10.1007/s11251-019. 09485-2.

Wongupparaj, P., Sumich, A., Wickens, M., Kumari, V., \& Morris, R. G. (2018). Individual differences in working memory and general intelligence indexed by P200 and P300: A latent variable model. Biological psychology, 139, 96105 , https://doi.org/10.1016/j.biopsycho.201 8.10.009.

Yeung, P. S., Ho, C. S. H., Chan, D. W. O., \& Chung, K. K. H. (2019). Writing motivation and performance in Chinese children. Reading and Writing, 1-23. 